Adv. Geosci., 46, 1-10, 2019

https://doi.org/10.5194/adgeo-46-1-2019

(C) Author(s) 2019. This work is distributed under

the Creative Commons Attribution 4.0 License.

\title{
The European Climate Research Alliance (ECRA): Collaboration from bottom-up
}

\author{
Winfried Hoke $^{1}$, Tina Swierczynski ${ }^{2}$, Peter Braesicke ${ }^{1}$, Karin Lochte ${ }^{2}$, Len Shaffrey ${ }^{3}$, Martin Drews ${ }^{4}$, \\ Hilppa Gregow $^{5}$, Ralf Ludwig ${ }^{6}$, Jan Even Øie Nilsen ${ }^{7}$, Elisa Palazzi ${ }^{8}$, Gianmaria Sannino $^{9}$, Lars Henrik Smedsrud $^{10}$, \\ and ECRA network* \\ ${ }^{1}$ Karlsruhe Institute of Technology (KIT), Institute of Meteorology and Climate Research - Atmospheric Trace Gases \\ and Remote Sensing (IMK-ASF), Karlsruhe, Germany \\ ${ }^{2}$ Alfred Wegener Institute, Potsdam, Germany \\ ${ }^{3}$ University of Reading, Reading, UK \\ ${ }^{4}$ Technical University of Denmark, Department of Management Engineering, Lyngby, Denmark \\ ${ }^{5}$ Finnish Meteorological Institute, Weather and Climate Change Impact Research, Helsinki, Finland \\ ${ }^{6}$ Ludwig-Maximilians-Universität, Department of Geography, Munich, Germany \\ ${ }^{7}$ Nansen Environmental and Remote Sensing Center, and Bjerknes Centre for Climate Research, Bergen, Norway \\ ${ }^{8}$ Institute of Atmospheric Sciences and Climate-National Research Council (ISAC-CNR), Torino, Italy \\ ${ }^{9}$ Italian National Agency for New Technologies, Energy and Sustainable Economic Development (ENEA), \\ Climate Modelling and Impacts Laboratory, Rome, Italy \\ ${ }^{10}$ University of Bergen, Geophysical Institute, Norway, and Bjerknes Centre for Climate Research, Bergen, Norway \\ *A full list of the network appears at the end of the paper.
}

Correspondence: Winfried Hoke (winfried.hoke@ecra-climate.eu)

Received: 28 June 2018 - Revised: 5 December 2018 - Accepted: 20 December 2018 - Published: 17 January 2019

\begin{abstract}
The European Climate Research Alliance (ECRA) is an association of leading European research institutions in the field of climate research (http://www.ecra-climate.eu/, last access: 6 December 2018). ECRA is a bottom-up initiative and helps to facilitate the development of climate change research, combining the capacities of national research institutions, and inducing closer ties between existing national research initiatives, projects and infrastructures. ECRA works as an open platform to bring together climate researchers, providing excellent scientific expertise for policy makers and of societal relevance. The ECRA Board consists of representatives of ECRA partners and decides on governance, scientific priorities, and organisational matters.

Currently organized into four Collaborative Programmes, climate scientists share their knowledge, experience and expertise to identify the most important research requirements for the future, thus developing a foresight approach. The CPs cover the topics: (1) Arctic variability and change, (2) Sea level changes and coastal impacts, (3) Changes in the hydrological cycle and (4) High impact events. The CP activ-
\end{abstract}

ities are planned in workshops and participation is open to all interested scientists from the relevant research fields. In particular, young researchers are actively encouraged to join the network. Each CP develops its joint research priorities for shaping European research into the future. Because scientific themes are interconnected, the four Collaborative Programmes interact with each other, e.g. through the organization of common workshops or joint applications. In addition, the Collaborative Programme leads attend the Board meetings.

The different formats of ECRA meetings range from scientific workshops to briefing events and side events at conferences to involve different groups of interests. This facilitates the interaction of scientists, various stakeholder groups and politicians. A biennial open ECRA General Assembly that is organised in Brussels represents an umbrella event and acts as a platform for discussion and contact with stakeholders. This event is an excellent opportunity to jointly discuss research priorities of high societal relevance. 


\section{Introduction}

The European Climate Research Alliance (ECRA) is an association of leading European research institutions, aiming to bring together, expand and optimise expertise in climate research. The initiative is a platform for joint research planning by inducing closer ties between existing national research capacities and infrastructures. Unlike a project, ECRA is a long-term institution supported and driven by its members and participants, who set the agenda and direction of the network and conduct scientific research in various collaborations.

This article summarises the development and activities of ECRA with a focus on its organisation and management approaches.

\section{Development \& Organisation of ECRA: a bottom-up approach}

In 2011, scientists from a number of European countries ${ }^{1}$ recognised the lack of an organisation aligning and coalescing scientific programmes on climate research within Europe. The Executive Committee (ExCom) had its inaugural meeting (ECRA, 2011a), deciding to formally establish the European Climate Research Alliance (ECRA), an alliance for scientists from climate research, environmental or atmospheric sciences, and related fields - ECRA was born.

Contrary to many initiatives, ECRA is not a project, but a long-term network or organisation. There is hence no defined deliverable at a certain time, but an iterative process pushed forward by the Board with evolving topics and focus areas.

This raises substantial challenges in terms of project management, as the short and medium-term activities of ECRA are often directed by needs of the ECRA Executive Committee and activities promoted by the European Commission (e.g. organisation of the General Assembly, responding to European Commission scoping activities, ...). Elements of ECRA, e.g. events or publications, organised by ECRA are characterised as projects and are project managed mostly by the secretariat in collaboration with the ECRA Board and members.

The founders of ECRA are also participants, making the creation and formation of ECRA a bottom-up approach, facilitating a unified voice for climate research in Europe and legitimising the initiative among its members. The internal stakeholders - the members of ECRA - constitute the core of ECRA. A European research institution can apply for membership in ECRA; the institution is then an active core partner of ECRA. In addition, scientists from the member countries

\footnotetext{
${ }^{1}$ CEA/CNRS (France), CIEMAT (Spain), Climate Change Centre Austria (Austria), Consortium for Natural Resource Research/FMI (Finland), DTU (Denmark), ENEA (Italy), Helmholtz Association (Germany), KNMI (Netherlands), NCAS (UK), Norwegian Climate Centre (Norway), SMHI (Sweden).
}

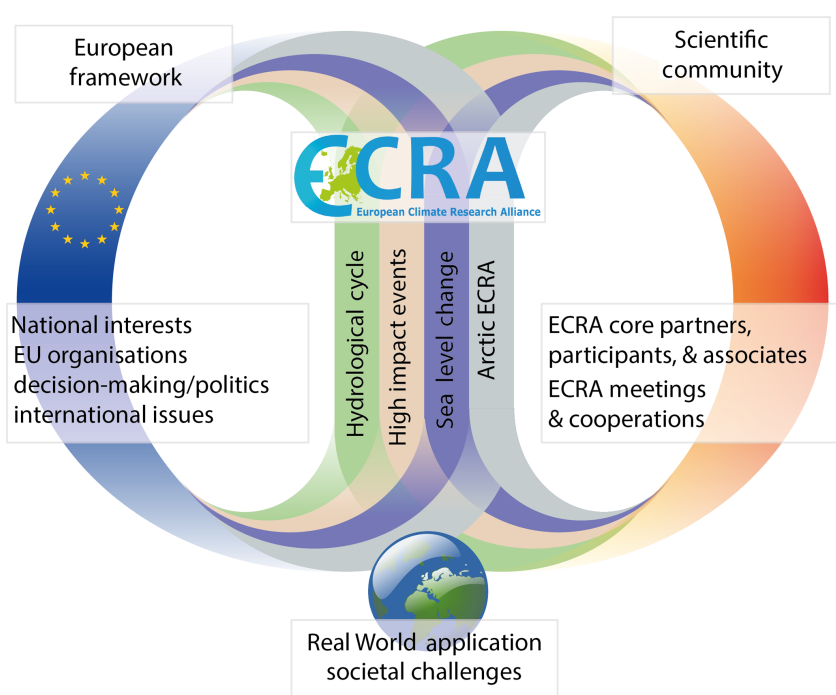

Figure 1. The interplay of ECRA, the European framework, and the scientific actorscape. ECRA's function is to connect the continuous activities of scientific research into the European Union and the other way around. Additionally, issues and criteria of real-world applications are included into the scientific agenda (C) ECRA, Earth: Freepngimg.com, 2018).

with significant scientific contributions to ECRA are considered participants, and other institutions with less contribution are called associates, who are all active in the Collaborative Programmes (hereinafter referred as CPs), which in turn are governed by the Board and the CP leads (ECRA, 2018). Figure 2 illustrates the organisation of ECRA.

To organise researchers and research areas more efficiently and to enable a better focus on the most pressing and relevant issues, initial identification of climate research key topics has taken place. Thus, research activities are organised within those four topical clusters, the "Collaborative Programmes" (CPs, see Sect. 3.1).

Members are convening twice yearly as the Executive Committee (ExCom Board meetings), the CP leads have equal rights as the Board members and are considered part of the Board. Figure 3 lists the affiliated institutes in ECRA. The work of members is currently organised within four established CPs.

Membership fees were introduced to finance the organisation: ECRA secretariat, organisation of meetings, material, website, etc., to be paid by each member on a yearly basis to the ECRA account (currently at the Chair's institution, at KIT, Germany). The secretariat and the administration of the host institution jointly maintain overview over funds and billings, payments are controlled by the ECRA Chair and the secretariat.

In addition to ECRA's role in linking European research organisations, the initiative is also looking towards the European Union and its frameworks and processes for science funding, decision-making and networking. In consequence, 


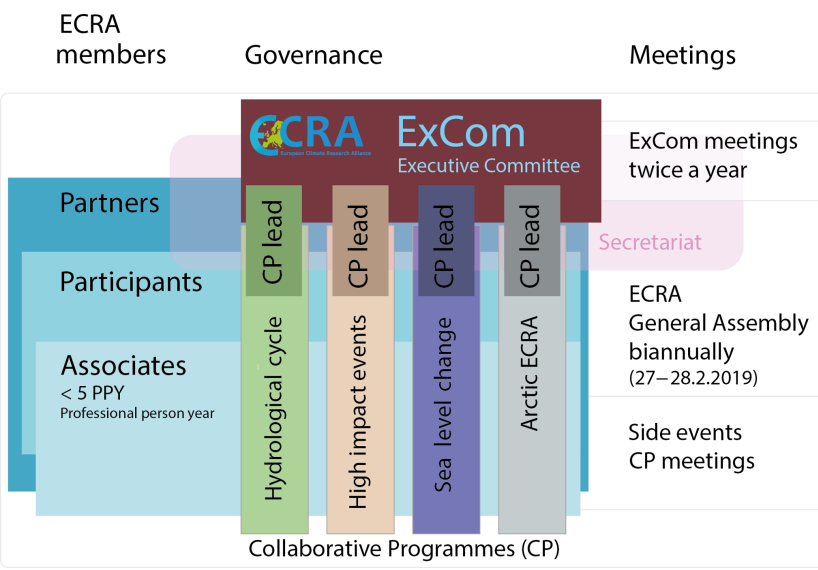

Figure 2. The organisation, members and meetings of ECRA. The four Collaborative Programmes frame research activities and are constituted of different members. Support and governance come from the Executive Committee and the secretariat (C ECRA).

the ECRA secretariat was situated in the Helmholtz-Office in Brussels, the "capital of Europe". One example of the numerous agencies, representations and secretariats in Brussels is JPI Climate, a network of European federal funding agencies with relevance to climate science. Since JPI Climate was also founded around the time of ECRA (JPI Climate, 2012) and has some topical overlap, ECRA received the status of observer and contributes through participation at meetings and networking.

Likewise, some of the members of ECRA have actively participated in the initial framing market-oriented initiatives such as the Copernicus Climate Change Service (C3S) and the ERA-NET Cofund for Climate Services (ERA4CS) as well as individual projects and project proposals, some of which are currently under review. Thus, what is discussed in ECRA is promoted in several ongoing and starting projects across Europe. This also extends to the international level, through the active participation or coordination by some of the ECRA members into broad initiatives such as the Group on Earth Observation (GEO) Initiative on mountains (GEOGNOME, Adler et al., 2018).

The two main duties - organisation of the scientific participants and "staying in the loop" of European activities can be illustrated as two processes brought together by the work of ECRA. The CPs streamline input from the European Union into their working programs, update activities, set agendas, and facilitate research. In consequence, new scientific results or topics are brought back e.g. to the European Commission (see Fig. 1).

Although ECRA has limited financial resources, it is continuously extending its sphere of influence by managing its network well, through its central secretariat in Brussels and its dedicated CP leaders. ECRA has a direct interactive influence in climate science in the countries and the networks of the ECRA members. ECRA members and PIs raise aware- ness of cross-disciplinary and interdisciplinary issues related to climate change, its impacts and risks through various presentations and as conveners of many different events.

The positioning of ECRA as unifying entity and representative in the European Union, as well as the support and management of the scientific community are facilitated by close partnership and collaboration between the active members of the Executive Committee, participating scientific actors (and their institutions) and the ECRA secretariat.

ECRA is a continuous activity and relies on the support of its members. The Board (ExCom) established a permanent secretariat in Brussels for the central management of ECRA activities. Priorities are set by the Board and take into account the developing landscape of e.g. new scientific ideas, EU actions, or new potential collaborations. The Board also decides on the procedures of ECRA and the secretariat: the ECRA Governance, for example, sets out the responsibilities of ECRA membership (membership fees, role of the Board and members, etc.).

The ECRA secretariat manages the communication within the network and organises project-based events and meetings in conjunction with the currently active CP leads. First, the planning process starts with defining the goals, topics and key participants, scrutinising the match between speakers and goal of the meeting, in a flexible and informal way. (A major task of the secretariat is to extend the ECRA Network and attract new members for collaborations). Events vary in format and type of audience. The meetings within the CPs focus on scientific exchange. Events such as the General Assembly are mainly organised as outreach events with a strong scientific foundation. Second, the experience gained at each event are critically analysed by the secretariat, the CP leads and the ExCom and help to shape future formats. The secretariat reports to the Board on relevant events and day-to-day topics.

The day-to-day management includes primarily the maintenance and extension of the ECRA network, which includes email and phone conversations and participation in meetings in Brussels and Europe; the administration (financial management and monitoring); and event organisation. Every month and at every Board meeting, the secretariat reports to the Board, discussing previous events and next steps.

\section{Building a Network for Science}

As mentioned in Sect. 2, the core members of ECRA are the CP leads and Board members. To extend the sphere of ECRA's influence and network, a range of measures are set in place, which are listed in the following subsections. However, ECRA does not have a defined Project Management goal other than to expand and strengthen the scientific network. Towards this goal, ECRA uses a range of tools (i.e. meetings, events, website, outreach), with successful activi- 


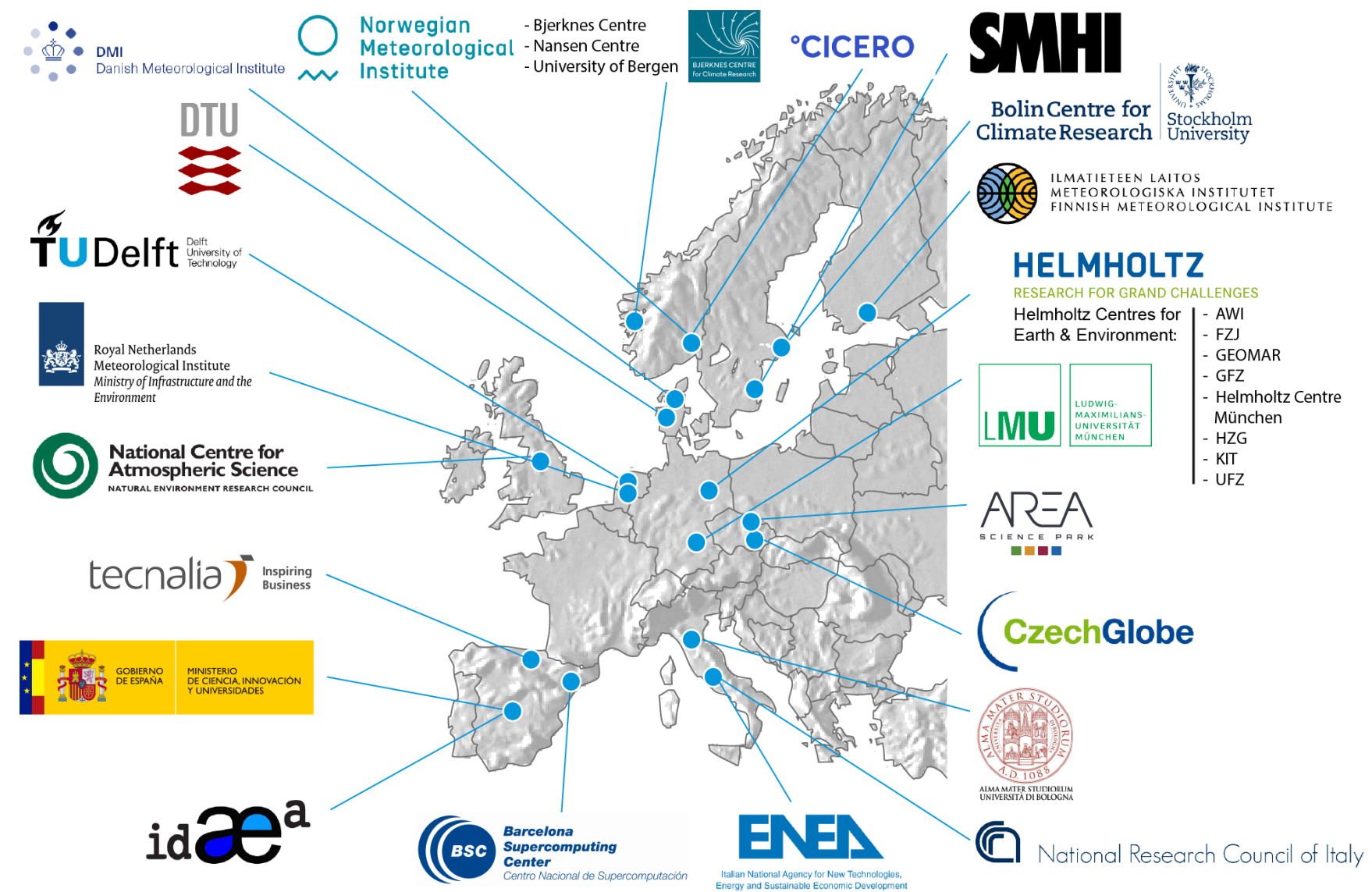

Figure 3. Members from nine countries within the ECRA organisation (@ ECRA).

ties but still room for improvement, e.g. an increase of staff in the secretariat or a closer collaboration with the Board.

ECRA has created a website (maintained by the secretariat) as an instrument to advertise and manage participation and to present the activities of the CPs. A long- or mid-term collaboration between actors under the ECRA umbrella depends on a two-way interaction: ECRA, as an organisation, benefits from the recognition of the scientific community; scientists, policy-makers, administrators and others can use ECRA as a network and asset to connect with each other and to gain and exchange knowledge. Initiatives facilitating this connection and exchange include ECRA-organized "Parliamentarian Lunches" held at the Parliament of the European Union in Brussels (e.g. a Science Briefing for Policy Makers on "The Changing Mountains of Europe - Water Resources and Ecosystems at Risk", 15 October 2013, Brussels), coorganized side events with high-level presentations and panel discussions on latest findings in climate and climate impact research and research needs (e.g. a Panel Discussion on "Societal Challenges related to climate change impacts on the hydrological cycle - risk analysis, vulnerability and adaptation" held at the "Climate Change and Water Conference", 5 February 2018, Tours, France) or general ECRA appear- ances at international scientific conferences (e.g. Climateurope Festival 2017 and 2018).

\subsection{Collaborative Programmes: the core of ECRA}

Scientific advancement is the central idea of ECRA. Iterative discussions in the Executive Committee meetings compiled the most relevant, pressing, and user-relevant topics early on into four Collaborative Programmes $(\mathrm{CP})^{2}$.

Arctic Climate Stability and Change ("Arctic ECRA")

Sea Level Change and Coastal Impacts

Changes in the Hydrological Cycle

High Impact Events and Climate Change

To create an effective organisation of science partners, the ECRA Governance Document defines the CPs as "strategic and ambitious programmes with many partners and interrelated climate research activities" (ECRA, 2018). The organisational centre of each $\mathrm{CP}$ is the lead or leads, one or two

\footnotetext{
${ }^{2}$ More information at http://ecra-climate.eu/activities-events/ collaborative-programmes (last access: 6 December 2018).
} 
persons of a member country who, on one side, are in close contact with the $\mathrm{CP}$ participants conducting research. On the other side, they have a seat in the ECRA ExCom Board and can participate in managerial discussions; hence connect the Board's decisions to the community.

Topical and strategic exchanges are encouraged during the ExCom and General Assembly meetings, providing new stimuli to the CP leads, scientists and the secretariat. This feeds back through the secretariat and the Board, who follow up developments and discuss priorities.

Within the four CPs modellers and experimentalists from different fields (e.g. physics, geology, hydrology, meteorology, oceanography, and many more) connect and coordinate their work. The topics of and within the CPs and the number of the CPs are flexible and follow the demand of ECRA participants. The ExCom Board (including the CP leads) is continuously overseeing the overall ECRA alignment and how the CPs are managed by their leads. If critical mass for a new $\mathrm{CP}$ is reached the governance allows for the creation of it.

To effectively inform the ECRA community, the secretary and designated partners are tasked to participate in different events. The secretariat attempts to follow up on the current climate-research related activities from different areas. For example, ECRA is commonly represented at a number of topical meetings to advertise possible future collaborations, e.g. also in the context of climate services.

Each CP consists of dozens of scientists, some just want to stay up to date through the network, and some are more involved and actively contribute to the progress of the CP. $\mathrm{CP}$ leads and the secretariat actively encourage all members to engage in the scientific processes. Some participants are members in several CPs, as the four topics have overlapping research areas. In consequence, some $\mathrm{CP}$ events are in fact organised conjointly. Examples include two interdisciplinary workshops organized by the "Changes in the Hydrological Cycle" and "High Impact Events and Climate Change" CPs: "Extreme events in a changing climate - Challenges and perspectives in hydro-meteorological modeling" and "Hydrological Cycle and High Impact Events" were held as side events to other meetings (CORDEX, May 2016; ECRA General Assembly, 2017). This was done to save travel efforts and to allow more participants to join, exceeding the number of regular participants from the ECRA community. Discussed were topics from different fields (climate science, (eco)hydrology, social sciences and socio-economics).

The next four sub-sections briefly introduce the scientific activity of the CPs and highlight Project Management aspects, where existing. However, CP leads' activities are similar to those of the secretariat: decisions are made by the Board or by the lead personally (informally or formally), and the goals, timeline, milestones exist but are mostly not formalised or documented.

\subsubsection{Arctic Climate Stability and Change}

Work in the scientific realm is always subject to change: the amount of participants and activities, the importance of topics within CPs, and even the titles of the CPs are not fixed and under permanent scrutiny by the community. An example of how the ambitions in the different CP's have varied over time is the Arctic ECRA CP. The Arctic CP was very active between 2012 and 2016. This resulted in the first briefing document in 2013 about ongoing Arctic Change with a length of four pages. In 2014 the full 30-page strategy and work plan was written. Both of these were based on scientific discussions during workshops, and the collaborative iteration between these participants lead by the CP coordinators. These documents were provided as guidance on how the scientific focus could be in the subsequent Horizon 2020 call of the European Union. Arctic ECRA participants were active in forming many of the projects that were funded in 2016. The three large funded Arctic Horizon 2020 projects were APPLICATE, INTAROS and Blue-Action. The project leader of APPLICATE, Thomas Jung from Alfred Wegener Institute, was one of the previous CP coordinators, and used ECRA as an efficient platform to build a consortium for the application. Arctic ECRA also contributed to creating the EU Polar-NET project. All of these projects ${ }^{3}$ will run until 2020.

Due to the large number of projects presently active in coordinating Arctic science, the need of the coordinative platform within ECRA has decreased, also decreasing the activity in this CP. However, new themes might replenish existing CPs or new topics might replace existing CPs. ECRA always welcomes new members that provide suggestions for reshaping or adding CPs. Scientific actors are invited to contact the secretariat to be involved in the activities of ECRA (e.g. mailing lists, General Assembly).

Well-connected and active researchers have busy agendas. It has thus proven to be a challenge to find new coordinators to take on the lead of this CP. This suggests to plan longterm with CP leads and Board members, in order to prepare personal changes in advance, and find scientists that have the right balance between experience and available time that can use the $\mathrm{CP}$ for constructive project coordination at a European level.

\subsubsection{Sea-level Change and Coastal Impact}

Even though sea level rise impacts have already been identified in the literature as a critical variable for the establishment and maintenance of coastal biotic communities, as a threat to

\footnotetext{
${ }^{3}$ APPLICATE, Advanced Prediction in Polar regions and beyond: modelling, observing system design and LInkages associated with a Changing Arctic climaTE, http://www.applicate.eu/ (last access: 10 December 2018); INTAROS, Integrated Arctic Observation System, http://www.intaros.eu/ (last access: 10 December 2018); Blue-Action project, Arctic Impact on Weather and Climate, http: //www.blueaction.eu/ (last access: 10 December 2018).
} 
biodiversity and as being responsible for the increasing magnitude and spatial extent of storm surge flood hazard, little has been discussed regarding the dimensions of the changes to come. Therefore, more research is needed concerning methods to assess the effects of climate change, establish sea level confidence thresholds, and to create and implement adaptation strategies to face the most severe sea level rise impacts, particularly those associated with low-probability but high-impact changes. In this context the goal of the Sea-level and Coastal Impacts CP is to facilitate knowledge sharing and integration from multiple research fields, coastal managers and policymakers in order to develop an appropriate overall analysis and evaluation methodology, to design adequate adaptation strategies and to promote a substantial enhancement of public awareness. Key questions identified by the $\mathrm{CP}$ are: How can coastal sea level projections be improved, at global, regional and local scales?; How can coastal impact assessment, adaptation, and risk management be enhanced?; How do we best achieve a common understanding of the science and risks amongst stakeholders, policymakers and scientists? As a result of the focus of these questions, the $\mathrm{CP}$ has recently had a workshop, produced a white paper and a special journal issue all built around these questions as a model. The white paper outlines the necessary focus European research, and governance needs to have in the face of the rising seas, while the special issue contains papers describing the state of art of the science as well as suggesting pathways for management and adaptation. The white paper and other documents are publicly available on the ECRA website.

The line of the above questioning is illustrative of the line of communication and collaboration that the $\mathrm{CP}$ works to establish as a model to reach the goal: to better integrate scientists, coastal engineers, and planners, as well as representatives from governing bodies in order for these to work closely together towards viable solutions for successful adaptation measures for the coastal zones. As mentioned, the CP leads organise activities to this goal by themselves, and the Board and secretariat gets involved to a smaller part and helps e.g. by dissemination or communication, or supporting event management and preparation.

\subsubsection{Changes in the Hydrological Cycle}

This CP develops around interconnected key aspects of the global water cycle: changes in precipitation at the global and regional scales and its often non-linear impacts on runoff; interaction between climate and hydrological processes at a variety of scales; observed and projected changes of the water cycle in specific climate "hot-spot" regions such as the Mediterranean and mountain areas. This is because these areas, which provide essential goods and services to human societies, respond more rapidly and intensely to climatic changes and anthropogenic pressures than other regions and thus can serve as sentinels of climate change impacts. Study- ing the above listed topics integrates two different sources of information: observations (in-situ and satellite data) and models (spanning from global and regional climate models of the Earth System connected to process-based, ecohydrological, ecosystem and impact models through downscaling methods). Both components are complementary and allow for gaining insight on their respective benefits and drawbacks. Current activities include more impact-oriented research to better blend with information regarding the dynamics of exposure, vulnerability and resilience to improve scientific projections and predictions of change in order to respond to crucial societal challenges and to support adaptation and mitigation strategies. This reflected into new ways of organising workshops and joint initiatives with other CPs, especially involving a wider cooperation with hydrologists, social scientists or economists.

Similar to the CP "Sea Level Change", this CP's leads are engaging in both the CP and the ECRA on a higher level of organisation. The discussions from the scientific work are introduced to the ECRA Board, and the Board's decision are brought back to the scientific work within the $\mathrm{CP}$.

\subsubsection{High Impact Events and Climate Change}

This CP examines how high impact events work, how they can be simulated accurately in numerical models and how we might be able to project future changes reliably. The $\mathrm{CP}$ further focuses at finding robust scientific means to present current and future extreme weather events and their impacts in regional and local scale. Several projects have supported the progress of this CP. To mention a few: EU-CORE-CLIMAX project investigated the usefulness of reanalyses in climate science and what should be improved to help the scientists and other users of the reanalysis data (Gregow et al., 2015). EU-RAIN project improved the risk analyses of infrastructure networks with respect to climate change impacts on extreme weather events in Europe. The interest has thus especially been in understanding reanalyses (Gregow et al., 2015 and references therein), the characteristics, frequency and severity of the events when using various types of observations (e.g. damaged volume of trees as an indicator of storm climate by Gregow et al., 2017), and how we can link the findings of from current climate to future climate using the climate models. The work is closely linked to climate service development, risk management and adaptation (Harjanne et al., 2017), since with respect to impacts we are interested in the exposure and vulnerability of the regions or locations. Many types of extremes and follow-up impacts, e.g. the relation between drought and forest fires (Lehtonen et al., 2016a), extreme precipitation and heavy snow loads (Lehtonen et al., 2016b), or severe freezing rain (Kämäräinen et al., 2017) might be associated with different regions.

As for the 'Changes in the Hydrological Cycle' CP, also for this CP both leads are from institutes in two different countries. This increases the information exchange, exposure 
and the potentially reached network for the scientific activities of the $\mathrm{CP}$.

\subsection{Initiatives \& External stakeholders}

The CPs represent the central scientific framework of ECRA. However, many European programmes, forums, networks and projects are highly relevant for science, science funding, spreading knowledge and networking. Each initiative follows individual goals and schemes, and also topics. ECRA is unique as the only scientific bottom-up organisation (founded by participants) to forward a better understanding of the climate system and sustainability. In the ECRA CPs science topics are based on the interaction of scientists, but also on the collaboration with stakeholders and policy needs. The interaction of science and stakeholders (e.g. engineers, public authorities etc.) is not straightforward because it needs a lot of iteration about specific practices, methods and requirements. Although such collaborations take time, it offers the great opportunity to better adapt on the societal needs and better approach cross-disciplinary work. Collaborations with organisations such as JPI Climate, the WMO, the Marine Board, and the European Polar Board are thus sensible since these share some of the topics. For example, ECRA has Observer Status at JPI Climate; members of the Board and the secretariat are actively following on activities and contribute. Also, the ECRA secretariat is conveniently based in Brussels where a number of networks and organisations regularly meet or organize workshops and events.

ECRA follows up on JPI Climate ${ }^{4}$ activities and creates connections to scientific activities, e.g. the Collaborate Programme "Sea Level Change and Coastal Impacts" could operate as a knowledge hub for JPI Climate (in progress). Besides activities organised on a European scale, ECRA members take also part in international projects initiated by the World Meteorological Organization $\left(\mathrm{WMO}^{5}\right)$, e.g. within the framework of the World Climate Research Panel or World Weather Research Panel (WCRP/WWRP). This participation enables ECRA to gain knowledge on other activities and research agenda.

\section{Facilitating science topics}

Communication within ECRA is a principal part of the organisational structure, and takes place through electronic communication between members and e.g. subscribers to the mailing list; and through the form of physical meetings and

\footnotetext{
4"Joint Programming Initiatives", founded under the European Research Area framework, more information at http://www.ec. europa.eu/research/era/joint-programming-initiatives_en.html (last access: 21 June 2018).

${ }^{5}$ World Meteorological Organization, an organisation of the United Nations (https://www.wmo.int/, last access: 6 December 2018).
}

events in different formats. The secretariat is organising the meetings reflecting the priorities and wishes of ECRA members (bottom-up).

\subsection{General Assembly}

In science as in most other lines of work, the most efficient mean of exchanging information are "offline" meetings. Smaller or bigger meetings represent a possibility to disseminate information, e.g. by presentations, and immediately discuss received information with the presenter, creating a feedback resulting in advancement of the topic. This is applicable for scientific issues, where debate is part of good scientific practice, but also for topics of management or administration.

The necessity for an ECRA General Assembly was already mentioned in the first ECRA ExCom meeting (ECRA, 2011b). The meeting has taken place two times since, in 2015 and 2017, and an upcoming General Assembly in February 2019 and, most likely, a 10-year anniversary General Assembly in 2021. The ECRA General Assembly as an umbrella event is meant to attract a high number of participants, both from ECRA core members itself, the participating scientists, but also from external fields such as members of the European Commission and Parliament, representatives of federal or regional representations in Brussels, and the general public. The General Assembly is an essential type of event for ECRA, because of its unparalleled participation and involvement of stakeholders.

Both General Assemblies were visited by more than hundred persons, with a ratio of scientists to administration, management or other of $1: 2.5^{6}$ (ECRA, 2015, 2017). The meeting of different kinds of actors in this context enables formal and informal communication and knowledge transfer, as well as networking: Scientists exchange on the selection of the most acute topics and basic research; scientists communicate with decision-makers on the priorities of research, research funding, and climate change relevant actions.

In 2017, the second ECRA General Assembly covered many projects and research results were discussed and presented to decision makers and scientists from various disciplines (113 participants from science, policy-making, and other, see http://ecra-climate.eu/ activities-events/ecra-general-assemblies (last access: 6 December 2018) for further information). For example, one of the key results presented within the CP for High-Impact Events was about the storms impacting Europe (Gregow et al., 2017). Gregow et al. (2017) could demonstrate that the power and intensity of storms has become three times more devastating during 1991-2010 compared to three earlier decades. This result was obtained by combining differ-

\footnotetext{
${ }^{6}$ The ratio is based on approximated categorisation of individual participants to either of the groups; based on both lists of participants in the file archives from the 2015 and 2017 General Assembly.
} 
ent science areas (forest sciences, mathematics, physics and meteorology), and as a result the dissemination was targeted at a diverse group of stakeholders. The information was obtained based on coordinated work conducted in several national projects. Based on the General Assemblies, and other meetings of ECRA, new scientific activities, meetings and goals are planned for every year.

The discussed issues and outcomes of the meetings are collected in meeting documentations. In addition, participants are asked to fill in a questionnaire which gave valuable input for the meeting assessment. (For the next General Assembly, it is also planned to distribute a questionnaire prior to the workshop.) These meeting documentations are valuable records of principle topics and challenges, which should be taken up in upcoming activities in ECRA (e.g. encouraging young scientists for science-policy work). In the past, meetings also resulted in joint publications or consortia for joint project applications. From ECRA experience, a biannual face-to-face meeting opens up for new ideas and crossdisciplinary and interdisciplinary collaborations. Therefore, it is important to give enough room and encourage the scientific exchange and discussions at the science-policy and science-industry interfaces.

\subsection{Executive Committee Meetings}

As part of its governance, the ECRA Board meets approximately twice a year. Since the establishment of ECRA in late 2011, there have been 15 Executive Committee (ExCom) meetings (most in Brussels, but also alternating in member locations). Each member country is represented by the ECRA institutional partners who send at least one person. Major organisational decisions within ECRA are made by voting (one vote for each partner ${ }^{7}$ ), following the rules of the ECRA Governance document (ECRA, 2018). In consecutive years, the Chair and Co-Chair of the ECRA Board are elected by a simple majority of the Board members.

ExCom meetings take place twice a year, all partners, participants and associates are invited. Additionally, representatives of JPI Climate are often joining as well as experts from organisations with topical overlap (e.g., European Energy Research Alliance, Horizon2020 and in the future Horizon Europe organisations). The majority of the meeting is a public meeting, and interested persons and organisations can ask for invitation, if their topical or organisational interest with ECRA seems relevant and useful to ECRA. The public part of the meeting serves to foster communication, exchange, brainstorming and discussion of new and existing topics. The internal part of the meeting is for ExCom members only, handling organisational, financial, staffing and ECRA-internal issues. The day-to-day management of ECRA activities is subsequently based on the ExCom decisions from both parts

\footnotetext{
${ }^{7}$ See Sect. 3 for differentiation between Partner, Participants, and Associates.
}

of the meeting. All decisions as well as the Action Items are recorded in the Board meeting minutes, the Action Items are controlled by the secretariat and, if not completed, brought back to the following Board meeting.

\subsection{Scientific meetings}

ECRA is an alliance of climate researchers, who meet on conferences, workshops, seminars, side-events or other events in order to do science. This is the scientific platform where everybody can join for scientific exchange and collaborate with relevant stakeholders. The institution of ECRA encourages and supports the organisation of workshops, collaborating with other initiatives and stakeholders; the secretariat and ECRA-funds can be used as facilitators. As mentioned, scientific topics of ECRA have been confined in four Collaborative Programmes, which represent the core of ECRA (see Sect. 3.1).

\section{Project Management}

As mentioned in Sect. 2, ECRA is a long-term initiative, however activities initiated by ECRA (by the secretariat or through its CPs) are characterised as projects. Thus, activities and processes in ECRA are organised in a project orientated way: the core team being the ECRA Board with the secretariat as operative centre; the Governance as a primary structure defining relationships and competences; the partners, participants and associates as network and the potential scientific community as extended network (to be approached and informed). Events, outreach activities and publications form individual projects with a set timeline and goal.

The "ECRA-projects", i.e. meetings, events, publications, networking activities, social media, do have a (often informal) defined structure: in most cases the goal is defined (e.g. reach out to maximum number of people), and a temporal frame is set (e.g. as soon as possible, before the beginning of a specific meeting, one tweet per week). The secretariat does not report to the Board on the specific Project Management aspects, only the achieved tasks are mentioned in the monthly reports or during the Board meetings, if at all. Hence, no formal documentation for reporting is created on most accounts.

Central for the dissemination of information is the ECRA homepage at http://www.ecra-climate.eu/ (last access: 6 December 2018). The website has up-to-date information on the organisation, activities, meetings, CPs, newsletters, internal areas for members, and much more. Current information is also distributed via social media and allows for communication back to ECRA. On Twitter, under @ECRA_Climate, updates and activities are shared. For example, the ECRA General Assembly 2017 was covered by a succession of tweets following the presentations and contributions.

A general ECRA mailing list has been established to inform members on events, activities, calls and to keep every- 
one "in the loop". Each Collaborate Programme has a separate mailing list to address the appropriate audience. For the secretariat, the database of email-addresses of partners, participants, associates, and interested external persons is a valuable asset in keeping an active base of users for ECRA. Through participation and outreach activities, this database is in constant growth and has contacts to persons and institutions from more than 40 countries.

The ECRA governance is facilitated by the secretariat and the Executive Secretary running it. The Executive Secretary is responsible for most tasks, e.g. organisation, administration and networking activities within ECRA. The ECRA secretariat invests time in networking and "spreading the word" about ECRA, on events or online. The bottom-up approach and the direct proximity between the secretariat and ExCom to the scientific community is a unique feature of ECRA, which helps to define ECRA as an outstanding organisation.

The tasks of project management consist among other of maintaining an overview of active and passive members. For dissemination of event information, membership information and scientific information, and outreach in general, especially the list of email-addresses is of high value. A newsletter is considered on a quarter-year or half-year basis, to provide information to readers new to ECRA (open to everyone, e.g. the interested public, decision-makers, administrators). Administrative and organisational aspects, such as organisation of events (i.e. General Assembly, ExCom meetings, and science meetings) and their accounting, and collection of membership fees also are done by the secretariat.

As any bottom-up organisation, ECRA faces challenges in preserving knowledge when the secretary is changing. However, due to a successful recruiting strategy and the dedication of the persons filling the post, ECRA has been able to preserve knowledge and to build on existing successes. The independent bottom-up organisation of the ECRA network enables fast responses from scientific experts (e.g. stakeholder consultations). However, science-policy exchange needs continuous performance that is often hampered through limitations in financial and personal capacities.

\section{Summary \& Conclusion}

The European Climate Research Alliance (ECRA) is a bottom-up organisation, benefiting from the activities of its members. The organisation is managed through its Brussels secretariat in conjunction with the ECRA Executive Committee, including the CP leads. The ECRA ExCom and the secretariat, in partnership with the CPs, can actively moderate the development of the CPs, setting new foci to develop the ECRA agenda and thus assuring continuous relevance to the European scientific community. Currently, four topical groups (CPs) are in operation: Arctic Climate Stability and Change ("Arctic ECRA"); Sea Level Change and Coastal Impacts; Changes in the Hydrological Cycle; and High Impact
Events and Climate Change. These four groups streamline many of the most pressing environmental and climate questions, and the secretariat provides the organisational and administrative support. ECRA will pursue its mission to provide new knowledge about climate change, disseminating new insights through workshops and side events, and by arranging an open biennial general assembly, presenting highlights of the previous years with an outlook to the future.

In ECRA, scientists are inter-linked at the science policy interface. This ensures the communication among scientists, crossing different disciplines and supporting the best translation of science topics for policy. Scientists have the opportunity to convey and discuss pressing science topics with political representatives on European and International level. This is bi-directional and scientists also learn from firsthand information how to make their scientific results valuable for policy and society. This is highly relevant for crossdisciplinary and applied science projects. In many meetings, the science-policy exchange "science for society" also highlights that there are barriers and still very few unknown practices in particular in approaching "climate services". The roadmaps of the European Commission need further experiences how to implement "climate services", e.g. through open discussion and platforms with scientists. Since 2011, ECRA supports this ongoing exchange with adaptive and useful tools from bottom-up, and is still collecting knowledge on how to efficiently manage ECRA towards the goal of the strengthening of the Climate research community.

Data availability. No data sets were used in this article.

Author contributions. The authors declare that they contributed evenly to the writing of this article.

Competing interests. The authors declare that they have no conflict of interest.

Special issue statement. This article is part of the special issue "Project management in geosciences: systems and practices for high-impact research". It is a result of the EGU General Assembly 2017, Vienna, Austria, 23-28 April 2017.

Acknowledgements. ECRA would like to thank the partners of ECRA for facilitating the functioning of the Alliance: Helmholtz Association (DE), the National Centre for Atmospheric Science (NCAS, UK), Italian National Agency for New Technologies, Energy and Sustainable Economic Development (ENEA, IT), Finnish Meteorological Institute (FMI, FI), Norwegian Meteorological Institute (NMI, NO), Research Centre for Energy, Environment and Technology of Spain (CIEMAT, ES), Technical University of Denmark (DTU, DK), and CzechGlobe (CZ). ECRA wants 
to thank the Executive Secretaries for their indispensable effort: Andreas Krell (2011-2014) and Tina Swierczynski (2014-2018); and Winfried Hoke (since March 2018).

The article processing charges for this open-access publication were covered by a Research

Centre of the Helmholtz Association.

Edited by: Sylvia Walter

Reviewed by: Friederike Hoffmann and one anonymous referee

Team list. The complete member list of the ECRA network can be found at: http://www.ecra-climate.eu/about-us/members (last access: 10 January 2019).

\section{References}

Adler, C., Palazzi, E., Kulonen, A., Balsiger, J., Colangeli, G., Cripe, D., Forsythe, N., Goss-Durant, G., Guigoz, Y., Krauer, J., Payne, D., Pepin, N., Peralvo, M., Romero, J., Sayre, R., Shahgedanova, M., Weingartner, R., and Zebisch, M.: Monitoring Mountains in a Changing World: New Horizons for the Global Network for Observations and Information on Mountain Environments (GEO-GNOME), Mt. Res. Dev., 38, 265-269, 2018.

ECRA: Minutes of the 3rd ECRA-Meeting, internal document, 21 January 2011, ECRA Secretariat, Brussels, 2011a.

ECRA: 1st Executive Committee meeting of the European Climate Research Alliance, 5 October 2011, ECRA Secretariat, Brussels, Minutes of the Meeting, available at: http://www. ecra-climate.eu/about-us/executive-committee(internal area, last access: 9 May 2018), 2011b.

ECRA: Participation ECRA General Assembly 25-26 March 2015, List of Participants, Internal document of the ECRA Secretariat, ECRA Secretariat, Brussels, 2015.

ECRA: Participation ECRA General Assembly 7-8 March 2017, List of Participants, Internal document of the ECRA Secretariat, Brussels, 2017.
ECRA: Version 5 of the ECRA Governing Document, to be ratified by the 16th Executive Committee Meeting in September 2019, ECRA Secretariat, Brussels, Belgium, 2018.

Freepngimg.com: Earth symbol in Illustration 1 available at: http://www.freepngimg.com/png/13540-earth-png-hd, last access: 3 May 2018

Gregow, H., Jylhä, K., Mäkelä, H., Aalto, J., Manninen, T., Karlsson, P., Kaiser-Weiss, A., Kaspar, F., Poli, P., Tan, D., Obregon, A., and $\mathrm{Su}, \mathrm{Z}$. : Worldwide survey of awareness and needs concerning reanalyses, and respondents' views on climate services, B. Am. Meteorol. Soc., 97, 1461-1473, https://doi.org/10.1175/BAMS-D-14-00271.1, 2015.

Gregow, H., Muzaffer, E. A., and Laaksonen, A.: Increasing large scale windstorm damage in Western, Central and Northern European forests, 1951-2010, Scientific Reports, available at: http: //rdcu.be/q66j (last access: 10 October 2018), 2017.

Harjanne, A., Haavisto, R., Tuomenvirta, H, and Gregow, H.: Risk management perspective for climate service development - Results from a study on Finnish organizations, Adv. Sci. Res., 14, 293-304, https://doi.org/10.5194/asr-14-293-2017, 2017.

JPI Climate: Joint Programming Initiative Climate Launch Event report, available at: http://www.jpi-climate.eu/media/default.aspx/ emma/org/10826603/JPI_Launch_Event_Brussels_FINAL.pdf (last access: 5 May 2018), 2012.

Kämäräinen, M., Hyvärinen, O., Jylhä, K., Vajda, A., Neiglick, S., Nuottokari, J., and Gregow, H.: A method to estimate freezing rain climatology from ERA-Interim reanalysis over Europe, Nat. Hazards Earth Syst. Sci., 17, 243-259, https://doi.org/10.5194/nhess-17-243-2017, 2017.

Lehtonen, I., Venäläinen, A., Kämäräinen, M., Peltola, H., and Gregow, H.: Risk of large-scale fires in boreal forests of Finland under changing climate, Nat. Hazards Earth Syst. Sci., 16, 239-253, https://doi.org/10.5194/nhess-16-239-2016, 2016a.

Lehtonen, I., Kämäräinen, M., Gregow, H., Venäläinen, A., and Peltola, H.: Heavy snow loads in Finnish forests respond regionally asymmetrically to projected climate change, Nat. Hazards Earth Syst. Sci., 16, 2259-2271, https://doi.org/10.5194/nhess16-2259-2016, $2016 \mathrm{~b}$. 